OPEN ACCESS

Edited by:

Sami Souissi,

Lille University of Science and

Technology, France

Reviewed by:

Alicia Estevez Garcia,

Institut de Recerca i Technologia

Agroalimentàries, Spain

Zhenhua Ma,

South China Sea Fisheries Research Institute (CAFS), China

*Correspondence:

Réjean Tremblay

rejean_tremblay@uqar.ca

Specialty section:

This article was submitted to

Marine Fisheries,

Aquaculture, and Living Resources,

a section of the journal

Frontiers in Marine Science

Received: 12 March 2021 Accepted: 23 April 2021

Published: 19 May 2021

Citation:

Mejri SC, Tremblay R, Audet C,

Wills PS and Riche M (2021)

Essential Fatty Acid Requirements in

Tropical and Cold-Water Marine Fish

Larvae and Juveniles.

Front. Mar. Sci. 8:680003.

doi: 10.3389/fmars.2021.680003

\section{Essential Fatty Acid Requirements in Tropical and Cold-Water Marine Fish Larvae and Juveniles}

\author{
Sahar Chauffour Mejri ${ }^{1}$, Réjean Tremblay ${ }^{2 *}$, Céline Audet ${ }^{2}$, Paul S. Wills ${ }^{1}$ and Marty Riche ${ }^{1}$ \\ ${ }^{1}$ Harbor Branch Oceanographic Institute, Florida Atlantic University, Fort Pierce, FL, United States, ${ }^{2}$ Institut des Sciences de \\ la Mer, Université du Québec à Rimouski, Rimouski, QC, Canada
}

To improve survival at early developmental stages (larvae and juveniles) of captive fish species, essential nutrients [i.e., essential fatty acids (EFA)] need to be identified. The physiological needs are likely to be different among species, particularly among those using different thermal habitats, because lipids are largely used to maintain cell membrane integrity (homeoviscous adaptation) in fishes. This review paper will focus on currently published research and the main results from our laboratories regarding optimum qualitative EFA requirements during larval and early juvenile stages in a warm-water marine species, the Florida pompano (Trachinotus carolinus), and a cold-water marine species, the winter flounder (Pseudopleuronectes americanus). To identify the qualitative optimal EFA requirements, we calculated the ratio of certain fatty acids (FA) in larval or early juvenile tissues to total FA present in the diet. This ratio indicates whether a specific FA from prey is selectively incorporated by larvae and juveniles. Overall, we found that young larvae from both cold- and warm-water species have greater demands for n-3 and n-6 highly unsaturated fatty acids (HUFA) than do larvae at weaning stages. However, the qualitative EFA requirements of the cold-water species at all early developmental stages were higher than those of the warm-water species. Enriched rotifer diets provided satisfactory amounts of omega 3 and omega 6 in Florida pompano, with small selective retention for docosahexaenoic acid (DHA), eicosapentaenoic acid (EPA), and arachidonic acid (ARA), suggesting a potential minor diet deficiency in these EFA. There were higher deficiencies in the cold-water species fed enriched rotifers, as demonstrated by the higher selective retentions of all EFA (DHA, EPA, and ARA), with the exception of larvae fed with copepods. The physiological needs in EFA for juvenile development seemed to be better met for both species when they were fed micro pellets. From the beginning of settlement and in young juveniles, qualitative values of $12 \%$ DHA, 10\% EPA, 5\% ARA, and 40\% PUFA of total FA seem to be required for winter flounder juvenile development. In Florida pompano, these requirements could be met until larger juvenile stages, with 15\% DHA, 3\% EPA, 2\% ARA, $2 \%$ DPA, and total PUFA below $30 \%$ of total FA. This review was done to aid future research aiming to develop nutritionally balanced microdiets or live-prey enrichment diets to satisfy the physiological requirements of captive tropical and cold-water marine fish species.

Keywords: warm-water fish, cold-water fish, essential fatty acids, larvae, juveniles, diet 


\section{INTRODUCTION}

Lipid energy is transferred from phytoplankton to fish via zooplankton. A good indication of the energetic importance of lipids for fish was demonstrated by Yaragina et al. (2000), who showed that total lipid energy is a predictor of reproductive potential in fish stocks. During digestion, ingested lipids containing fatty acid chains of more than 14 carbons are hydrolyzed to yield free fatty acids, monoacylglycerols, and - in the case of phospholipids (PL) - lysophospholipids. These products pass through the mucosal wall of the small intestine, reform into triglycerides, and are transported to tissues by chylomicrons in the blood (Budge et al., 2006). Small-chain fatty acids $\left(<14^{\circ} \mathrm{C}\right)$ are transported directly to the liver to be oxidized. Thus, long-chain fatty acids can be preserved during the digestive process and selectively retained by fish to sustain later development.

Aquaculture development of new marine fish species is challenged by a critical knowledge gap concerning the nutritional needs at larval and early juvenile stages. The optimization of feeding conditions and the nutritional quality of starter diets, which are generally at least partially made up of enriched live prey, directly influence the success of these early stages as estimated by growth and survival surveys. Lipids are a major nutritional constituent and are the main source of metabolic energy sustaining the rapid development of early stages (Glencross, 2009). Lipids provide at least two-thirds more energy per gram than proteins or carbohydrates (Parrish, 2013). Of the different lipid classes, neutral lipids, including wax esters, sterols, free fatty acids, and triglycerides have a rapid turnover and can satisfy short-term energy needs (Budge et al., 2006), while the $\beta$-oxidation of saturated fatty acids (SFA) releases energy more efficiently than polyunsaturated fatty acids (PUFA; Langdon and Waldock, 1981).

Despite years of research, lipids remain the least wellunderstood nutrient (Glencross, 2009; Parrish, 2013). Some fatty acids are considered as essential fatty acids (EFA) for marine fish development because they cannot be biosynthesized to support normal development (Glencross, 2009). EFA are involved in different physiological functions, including reproduction, immunity, ion balance regulation, muscle contraction, cell adhesion, vascular tone, buoyancy control, and brain and eye development, and thus directly affect the growth and survival of marine animals (Glencross, 2009; Pond and Tarling, 2011; Gurr et al., 2016). These EFA are mainly from two related families ( $\mathrm{n}-3$ and $\mathrm{n}-6)$ and from three longchain PUFA: docosahexaenoic acid (DHA, 22:6n-3), eicosapentaenoic acid (EPA, 20:5n-3), and arachidonic acid (ARA, 20:4n-6), which have long been considered crucial. DHA and EPA have important roles in the maintenance of membrane fluidity while ARA and EPA are precursors of bioactive eicosanoids (Tocher, 2010). During larval development, DHA is preferentially incorporated into nervous and retina tissue (Izquierdo et al., 2000; Villalta et al., 2008), and growth anomalies and high mortality are observed when DHA is insufficient (Tocher, 2010). Other dietary FA, including linoleic acid (LA; 18:2n-6) and $\alpha$-linolenic acid (LNA; 18:3n-3), are stored in muscle tissue to meet physiological needs and are also related to fish growth and survival to some extent (Jardine et al., 2020). These FA are precursors of DHA, EPA, and ARA, but as already pointed out; the activities of the specific enzymes (desaturase and elongase) responsible for their biosynthesis are limited in most marine species.

Artemia and rotifers contain high levels of $\mathrm{PL}$, which are considered valuable for fish nutrition (Tocher et al., 2008), and they are the main live prey used in aquaculture. However, their low levels of EFA are not adequate for early life stages, so they must be enriched before being used as prey (Øie et al., 2011). In contrast, copepods, which are natural fish prey in the wild, are rich in phospholipids and EFA, but their laboratory production is complex and challenging (Drillet and Lombard, 2015). Although the PL content per dry weight (DW) in rotifers and Artemia cannot be manipulated, their fatty acid composition can be modified with the use of enrichments (Castell et al., 2003; Monroig et al., 2003; Seychelles et al., 2009; Hawkyard et al., 2015).

One interesting method used to determine the prey's nutritional quality in terms of EFA is the ratio of specific fatty acids in larval or early juvenile tissues to the total fatty acids present in the prey [the fish to diet (FD) ratio]. This FD ratio indicates whether a specific prey fatty acid is selectively incorporated by larvae and juveniles (Copeman et al., 2002; Pernet and Tremblay, 2004; Gendron et al., 2013; MartinezSilva et al., 2018). If the relative proportion of a specific fatty acid in larvae or juveniles to their diet is equal to or below 1 , then the specific requirement for this fatty acid could be considered as satisfied. In contrast, if the relative proportion is higher than 1, then we would presume that this FA is selectively incorporated by larvae or juveniles, which may indicate a potential dietary deficiency.

The objective of this review paper is to present published research regarding live-prey diets used in early developmental stages of Florida pompano (Trachinotus carolinus) and winter flounder (Pseudopleuronectes americanus), two contrasting models from tropical and temperate coastal habitats, respectively, to determine whether their ontogenic EFA needs are comparable. Both species are commercially important and contribute to the economies of their distribution range, compelling the aquaculture industry to search for more effective rearing methods. Our aim is to examine whether FD ratios can give information about differing needs through the first stages of development and how these needs are comparable between tropical and cold-temperate species. To estimate potential dietary deficiencies in EFA, we used the FD ratio as an optimization tool. The FD ratio as well as compositions of fatty acid that are considered to be essential or of special importance for larval and juvenile development [18:2n-6, 18:3n-3, 20:4n-6, 20:5n-3, 22:6n-3, total n-3, total n-6, SFA, monounsaturated fatty acids (MUFA), and PUFA] are presented and compared between relatively similar ontogenic stages in the two species considered (Table 1).

The lipid composition of larvae and/or juveniles has been presented in detail for Florida pompano (Cavalin and Weirich, 2009; Hauville et al., 2014, 2016; Rombenso et al., 2016, 2017; 
TABLE 1 | Age or mass of larvae and juveniles of the two species compared in this review.

\begin{tabular}{lll}
\hline Ontogenic stage & Florida pompano & Winter flounder \\
\hline Mouth opening & No data available & $4 \mathrm{DPH}$ \\
Live prey feeding & $9 \mathrm{DPH}$ & $15-22 \mathrm{DPH}$ \\
Weaning & $17 \mathrm{DPH}$ & $26 \mathrm{DPH}$ \\
Beginning of settlement & & $38 \mathrm{DPH}$ \\
Early settled juveniles & & $30 \mathrm{DPS}$ \\
$\begin{array}{l}\text { O+ juveniles } \\
\text { Juveniles }\end{array}$ & Around $40 \mathrm{~g}$ & 60 and $90 \mathrm{DPS}$ \\
\end{tabular}

Florida pompano (T. carolinus): larval rearing at $26-27^{\circ} \mathrm{C}$; winter flounder (P. americanus): larval rearing at $10^{\circ} \mathrm{C}$. DPH, days post-hatch; DPS, days post-settlement.

Jackson et al., 2020) and for winter flounder (Mercier et al., 2004; Seychelles et al., 2011, 2013; Vagner et al., 2013; Bélanger et al., 2018; Martinez-Silva et al., 2018). While these studies examined different developmental stages, we have merged the results for the purpose of comparison.

\section{NUTRITIONAL RATIOS AND FATTY ACID COMPOSITION}

\section{FD Ratio in Larvae}

Florida pompano larvae at the live-prey feeding period-fed several enriched rotifer diets [Isochrysis sp. (ISO), Pavlova sp. (PAV), Protein Selco Plus (PS+), Ori-Green (OG), Protein highly unsaturated fatty acid (HUFA; PH), and AlgaMac 3050 (AM)] showed specific needs for DHA, EPA, and ARA, with selective retention of these three EFA (Figure 1). The FD ratio for EPA was relatively close to one in larvae fed the different enriched diets, particularly for the AM- and OG-enriched diets, showing accumulations of up to $7 \%$ of total FA (Table 2). Exceptions were noted for ISO-enriched diets, which showed ratios near 1.5. DHA requirements seemed to be satisfied by most diets, with an average of $15 \%$ of total FA (Table 2) and the best FD ratio for DHA being observed in larvae fed diets enriched with PAV and PH (ratio = 1.053 and 1.056, respectively). This suggests that these diets satisfied most physiological needs of the larvae at this developmental stage. All diets showed FD ratios above one for ARA, suggesting that these enrichments did not satisfy the requirements for this PUFA (Figure 1). The maximal ARA accumulation observed at the live-prey feeding stage was $3.5 \%$ of total FA (Table 2), with FD ratios between 1.26 and 1.89 depending on the diet. LA and LNA were not selectively retained by larvae at this stage, with ratios $<1$ and low relative percentages of LNA ( $0.6 \%$ of total FA; Table 2). However, two diets (PAV and AM) seemed to better supply the LA and LNA requirements, with FD ratios equal to one (Figure 1). Overall, total omega $3(n-3)$ and omega $6(n-6)$ FD ratios were close to one for all diets (Figure 1), suggesting that the different enriched rotifer diets provided satisfactory amounts of n-3 and n-6 PUFA for larvae at the live-feeding stage.

At the weaning period [17 days post hatch (DPH)], Florida pompano larvae were fed different microdiets (Gemma, Otohime, and LR803) and generally showed FD ratios close to one.
TABLE 2 | Relative percentages of fatty acids in Florida pompano (T. carolinus) larvae at live prey feeding and weaning (9 and $17 \mathrm{DPH}$, respectively; Cavalin and Weirich, 2009; Hauville et al., 2014).

\begin{tabular}{lcc}
\hline & Live prey feeding & Weaning \\
\hline 18: $2 \mathrm{n}-6(\mathrm{LA})$ & $6.58 \pm 2.53$ & $16.32 \pm 10.45$ \\
18: $3 \mathrm{n}-3(\mathrm{LNA})$ & $0.59 \pm 0.28$ & $2.22 \pm 0.99$ \\
$20: 4 \mathrm{n}-6(\mathrm{ARA})$ & $3.55 \pm 0.41$ & $0.47 \pm 0.15$ \\
20: $5 \mathrm{n}-3$ (EPA) & $7.28 \pm 1.22$ & $5.20 \pm 2.65$ \\
$22: 6 \mathrm{n}-3(\mathrm{DHA})$ & $15.06 \pm 4.59$ & $8.57 \pm 2.29$ \\
Total $n-3$ & $28.64 \pm 2.31$ & - \\
Total $n-6$ & $14.80 \pm 1.70$ & - \\
SFA & - & $29.99 \pm 1.87$ \\
MUFA & - & $39.80 \pm 3.87$ \\
PUFA & - & \\
\hline
\end{tabular}

Data represent mean $\pm S D$ from all diet treatments at 9 and $17 D P H$. $L A$, linoleic acid; $L N A$, linolenic acid; ARA, arachidonic acid; EPA, eicosapentaenoic acid; DHA, docosahexaenoic acid; SFA, saturated fatty acids; MUFA, monounsaturated fatty acids; and PUFA, polyunsaturated fatty acids.

One exception was noted: EPA ratios were between 1.47 and 1.86, indicating selective retention for this EFA and potential diet deficiencies. Among the three microdiets, Otohime micro pellets followed by LR803 seemed to be the most appropriate; they fulfilled the physiological fatty acid requirements of larvae at the weaning stage, with a PUFA ratio equal to 1.01 for both diets (Figure 1).

In winter flounder larvae, overall larval contents in neutral EPA and DHA and in polar DHA were higher at the mouthopening stage, reflecting the maternal nutritional contribution (yolk sac; Table 3). Overall, EPA and DHA contents were usually higher in polar than in neutral lipids, as reflected by the total $n-3$ value (Table 3 ). Once larvae started feeding, FD ratios for the neutral lipids showed that the three EFA (ARA, DHA, and EPA) were immediately retained (FD values much greater than one), regardless of the diet [rotifers enriched with Selco or days' post settlement (DPS)]. For most diets, the high retention levels of EFA in the neutral fraction were maintained throughout development, but larvae fed rotifers enriched with Sparkle or copepods showed ratios near or below one (Figure 2). This may be related to crucial biological needs, since EFA are important for physiological functions. Indeed, FD ratios for polar lipid fractions were mostly greater than one whatever the diet or the larval stage of development, except for larvae fed copepods at the live-prey feeding stage (Figure 2). For each EFA, the use of copepods as live prey decreased the FD ratio of polar lipids in larvae relative to diet content, but the ratio was slightly greater than one for ARA and EPA. In these larvae, overall LNA contents were usually very low. This is not surprising since Artemia were not included in the larval diets (Table 3), and Artemia are usually characterized by high LNA levels (Rocha et al., 2017). The requirements for omega n- 6 seemed to be met regardless of the diet, as indicated by their elimination in neutral lipids and their incorporation into polar lipids at percentages lower than those found in the different diets (Figure 2). However, the sum of omega n-3 showed ratios suggesting potential feed deficiency $(>1)$, particularly in the polar fraction, indicating that larval needs were not met except when copepods were used as live prey. 

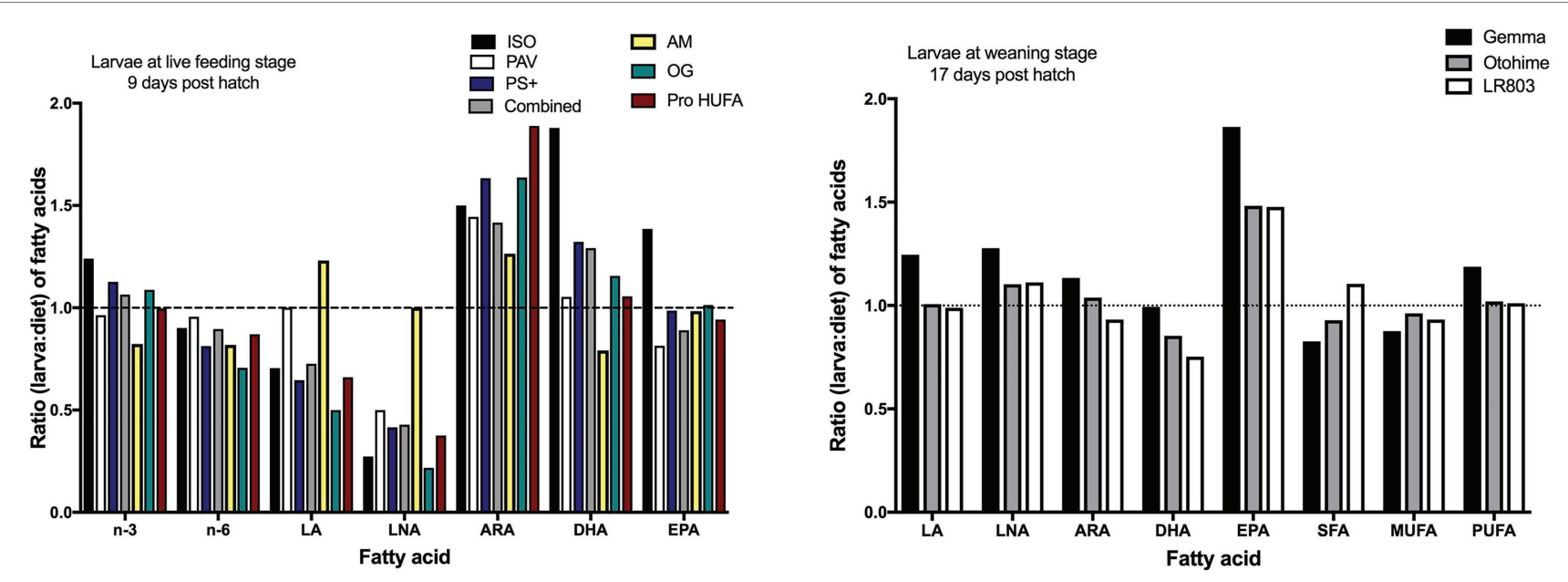

FIGURE 1 | Ratio (larva: diet) of fatty acids in Florida pompano (Trachinotus carolinus) larvae at the live feeding [9 days post hatch (DPH)] and the weaning period (17 DPH). Larvae at 9 DPH were fed several enriched rotifer diets: two microalga concentrates [lsochrysis sp. (ISO) and Pavlova sp. (PAV)], a semi-moist paste [Protein Selco Plus (PS+)], a combination of the three (Combined), and three dry enrichment diets [AlgaMac 3050 (AM), Ori-Green (OG), and Protein highly unsaturated fatty acids (HUFA; PH); Cavalin and Weirich, 2009]. Larvae at 17 DPH were fed three microdiets [Gemma, Otohime, and a reference diet (LR803); Hauville et al., 2014]. The dashed lines (ratio = 1) indicate equal amounts of fatty acids in the larvae and in the diet. LA, linoleic acid; LNA, linolenic acid; ARA, arachidonic acid; DHA, docosahexaenoic acid; EPA, eicosapentaenoic acid; SFA, saturated fatty acids; MUFA, monounsaturated fatty acids; and PUFA, polyunsaturated fatty acids.

\section{FD Ratio in Juveniles}

Only a few papers (Rombenso et al., 2016, 2017; Jackson et al., 2020) have discussed the physiological needs of Florida pompano juveniles in terms of fatty acids. In these studies, docosapentaenoic acid (DPA) was also observed in juvenile tissues. We have included it in this review since it has been identified as a potential EFA (Parrish et al., 2007). Rombenso et al. (2016) assessed the fatty acid composition in different tissues of Florida pompano juveniles $(43.4 \pm 0.2 \mathrm{~g})$ following fish oil replacement (Table 4; Figure 3). Juveniles were fed six different diets for 8 weeks; the diets contained menhaden fish oil, 25:75 blends of fish oil and standard soybean oil, MUFA-enriched soybean oil, SFA-enriched soybean oil, palm oil, or poultry fat. ARA was selectively retained in the brain irrespective of the diet that was provided (FD ratio $\geq 1.35$ ), suggesting a physiological need for this EFA in this tissue. However, the same FA was present at satisfactory levels in the eye, with FD ratios not exceeding 1.14 for all diets (Figure 3). The same tendency was observed in the liver except for juveniles fed the palm diet (ratio $=1.57$ ). ARA ratios were equal to zero in the muscle tissue of all juveniles, suggesting that ARA is not required in muscle tissue at this stage and is probably not used for energy purposes (Figure 3). On the other hand, DHA and DPA seemed to have been strongly retained in all tissues, with higher selective retention in the brain and eye. FD ratios for DHA were $>2.2$ in the eyes of juveniles fed the SFA soy and MUFA soy diets. The FD ratio in brain tissue was as high as 3.28 for the same diets. Higher DPA retention levels were also observed in the eye, with FD ratios $\geq 2.22$ in juveniles fed all diets, suggesting the importance of this FA in eye development. FD ratios for EPA were $\leq 0.5$ in all tissues for all diet treatments, which suggests that diets with EPA levels below 3\% of total FA (Table 4) fulfilled EFA needs at this developmental stage. Other PUFA, such as LA and LNA, showed different trends in different tissues. FD ratios for LA were < 1 in all tissues except for muscle tissue in juveniles fed the fish diet; these had an FD ratio equal to 1, suggesting that this FA might be used for energy purposes. There is little or no physiological need for LNA, as evidenced by the lack of retention in any tissue (ratio $<0$ ) combined with levels below $2 \%$ in muscle and eye and $0 \%$ in liver and brain (Table 4). We suggest that LNA was used mostly as an energy substrate. FD ratios for SFA, MUFA, and PUFA were all close to one in each studied tissue (Figure 3).

Rombenso et al. (2017) also evaluated the requirements for EPA and DHA in Florida pompano juveniles (41.0 $\pm 0.5 \mathrm{~g})$ by feeding them for 8 weeks with diets containing fish oil, beef tallow, or beef tallow partially or fully supplemented with EPA, DHA, or both. It was interesting to see that ARA was more balanced in the brain tissue for fish fed beef tallow supplemented with EPA and DHA (FD ratio = 1.14), while this same fatty acid was more balanced in the eye tissue with all diets, but not with the non-supplemented beef tallow diet (Figure 4). ARA was highly retained in liver and muscle tissue except for two diets (fish oil only and the fully supplemented beef diet), where FD ratios were equal to 0.92. DHA and DPA were still highly retained in all tissues. However, DHA and DPA FD ratios were 1.1 and 1.28, respectively, in the brain of juveniles fed the fully supplemented beef diet (Figure 4), highlighting these specific needs in the brain tissue. The FD ratio for DHA was 1.04 in the eye tissue of juveniles fed the fully supplemented beef diet, which might suggest that this diet best fulfilled the DHA requirements of Florida pompano juveniles. EPA ratios in all tissues were comparable to a previous 
TABLE 3 | Relative percentages of neutral and polar fatty acids in winter flounder larvae (P. americanus) at mouth opening, live-prey feeding, and weaning (4; 15-16, 22; and 26 DPH, respectively; Seychelles et al., 2011; Martinez-Silva et al., 2018).

\begin{tabular}{|c|c|c|c|c|}
\hline & \multicolumn{4}{|c|}{ Larvae } \\
\hline & Mouth opening & \multicolumn{2}{|c|}{ Live-prey feeding } & \multirow{2}{*}{$\begin{array}{l}\text { Weaning } \\
26 \mathrm{DPH}\end{array}$} \\
\hline Neutral fatty acid & $4 \mathrm{DPH}$ & 15-16 DPH & $22 \mathrm{DPH}$ & \\
\hline 18: 2 n-6 (LA) & $4.55 \pm 0.78$ & $3.16 \pm 1.27$ & $1.39 \pm 0.06$ & $5.30 \pm 0.42$ \\
\hline 18: 3 n-3 (LNA) & 0 & $0.20 \pm 0.34$ & $0.34 \pm 0.12$ & 0 \\
\hline 20: 4 n-6 (ARA) & $2.45 \pm 0.07$ & $2.32 \pm 1.18$ & $1.29 \pm 0.30$ & $3.55 \pm 0.35$ \\
\hline 20: 5 n-3 (EPA) & $9.7 \pm 1.1$ & $6.5 \pm 3.2$ & $2.9 \pm 0.8$ & $3.6 \pm 1.3$ \\
\hline $22: 6$ n-3 (DHA) & $20.25 \pm 0.35$ & $7.86 \pm 4.81$ & $2.73 \pm 0.81$ & $7.30 \pm 2.12$ \\
\hline Total n-3 & $31.80 \pm 1.13$ & $17.96 \pm 9.63$ & $8.19 \pm 1.85$ & $19.75 \pm 3.32$ \\
\hline Total n-6 & $7.10 \pm 0.85$ & $5.82 \pm 1.83$ & $3.26 \pm 0.23$ & $9.15 \pm 0.92$ \\
\hline SFA & $29.60 \pm 3.90$ & $65.44 \pm 13.63$ & $74.41 \pm 16.00$ & $24.44 \pm 0.59$ \\
\hline MUFA & $27.43 \pm 3.51$ & $22.57 \pm 9.02$ & $13.2 \pm 8.0$ & $36.83 \pm 8.86$ \\
\hline PUFA & $42.97 \pm 1.59$ & $11.99 \pm 5.92$ & $12.38 \pm 8.34$ & $38.73 \pm 8.28$ \\
\hline \multicolumn{5}{|l|}{ Polar fatty acid } \\
\hline 18: 2 n-6 (LA) & $3.50 \pm 0.00$ & $4.15 \pm 0.66$ & $2.30 \pm 0.20$ & $4.90 \pm 0.71$ \\
\hline 18: 3 n-3 (LNA) & 0 & 0 & $0.40 \pm 0.01$ & 0 \\
\hline 20: 4 n-6 (ARA) & $3.55 \pm 0.07$ & $5.50 \pm 1.68$ & $2.90 \pm 0.01$ & $6.10 \pm 0.57$ \\
\hline 20: 5 n-3 (EPA) & $11.55 \pm 0.21$ & $8.75 \pm 4.92$ & $17.26 \pm 0.16$ & $9.55 \pm 0.49$ \\
\hline $22: 6$ n-3 (DHA) & $22.90 \pm 0.57$ & $13.75 \pm 3.48$ & $6.72 \pm 0.27$ & $12.35 \pm 4.74$ \\
\hline Total n-3 & $35.85 \pm 0.78$ & $27.09 \pm 1.60$ & $27.16 \pm 0.48$ & $28.1 \pm 4.9$ \\
\hline Total n-6 & $7.30 \pm 0.14$ & $10.15 \pm 2.28$ & $6.00 \pm 0.23$ & $11.35 \pm 0.21$ \\
\hline SFA & $34.33 \pm 0.78$ & $43.48 \pm 11.42$ & $52.45 \pm 14.50$ & $29.97 \pm 1.76$ \\
\hline MUFA & $20.03 \pm 0.76$ & $20.96 \pm 3.76$ & $13.75 \pm 2.76$ & $23.77 \pm 6.23$ \\
\hline PUFA & $45.57 \pm 1.07$ & $35.56 \pm 9.95$ & $33.81 \pm 12.60$ & $46.23 \pm 4.71$ \\
\hline
\end{tabular}

Data represent mean $\pm S D$ from all diet treatments. $L A$, linoleic acid; LNA, linolenic acid; ARA, arachidonic acid; EPA, eicosapentaenoic acid; DHA, docosahexaenoic acid; SFA, saturated fatty acids; MUFA, monounsaturated fatty acids; and PUFA, polyunsaturated fatty acids.

study conducted by the same authors (Rombenso et al., 2016); FD ratios $\leq 0.5$. LNA were only found in eye tissue and were zero in all other tissues (Figure 4), confirming that there was no specific physiological need for this FA at this developmental stage. FD ratios for LA were close to one in muscle, liver, and eye tissues for all diets tested, indicating an adequate supply of this FA. LA was not selectively retained in the brain tissue, which confirms that it is not required for brain development/function. In all tissues examined, FD ratios for SFA, MUFA, and PUFA were close to one (Figure 4), suggesting that most diets tested, except the beef diet, were suitable fatty acid sources for Florida pompano juveniles. Juveniles fed the beef-only diet showed selective PUFA retention in almost all tissues, suggesting that this diet did not provide enough omega n-3 and PUFA to allow proper juvenile development. Thus, diets for juvenile Florida pompano development should include around 2\% ARA, 3\% EPA, 2\% DPA, and 15\% DHA, for a total PUFA below 30\%, to sustain development.

Winter flounder juveniles showed low EFA accumulation in their neutral lipids until 60 DPS (Table 5), and no active retention in lipid reserves was observed except for ARA. Before 60 DPS, all EFA seemed to be directly incorporated into polar lipids, possibly in response to vital physiological requirements. Following settlement, DHA and EPA requirements seemed to be adequately met with the Gemma micro diet and diets of rotifers enriched with commercial Selco DHA protein or with INVE Selco sparkle in older fish, since the FD ratios of these EFA in the lipid polar fraction were below one (Figure 5). However, the FD ratio for ARA in the polar fraction was much greater than one in all diets (Figure 5), suggesting inappropriate enrichment for this FA. As juveniles grew, the relative content of fatty acids increased except for ARA, which remained close to values observed at the early juvenile stage (Table 5). Indeed, almost all FD ratios were below one in young juveniles (60 and 90 DPS), indicating that needs were met regardless of the diet, even though ARA was still actively retained (Figure 5). Thus, these results suggest that diets with $10 \%$ EPA, $12 \%$ DHA, more than 5\% ARA, and a total of $40 \%$ PUFA could be adequate to sustain proper development in winter flounder juveniles.

\section{QUALITATIVE ESSENTIAL FATTY ACID REQUIREMENTS FOR EARLY STAGES}

The qualitative requirements for EFA in Florida pompano larvae were the highest during the live-feeding period, when the relative percentages of DHA, EPA, and ARA represented 16, 7 , and $4 \%$ of total fatty acids, respectively (Figure 6). These findings are comparable to those obtained, at $8 \mathrm{DPH}$, in a closely related species; the golden pompano (Trachinotus ovatus). The authors suggested that at least 18\% DHA, 5\% EPA, and $3.5 \%$ ARA of total FAs are needed for the larvae to achieve optimal development and reduce deformities (Fu et al., 2021). During the weaning period, the requirements for DHA and ARA decreased by 50 and $75 \%$ from the live-feeding period, respectively ( 7 and $1 \%$ of total FA for DHA and ARA, respectively), while EPA percentages did not change (7\% of 


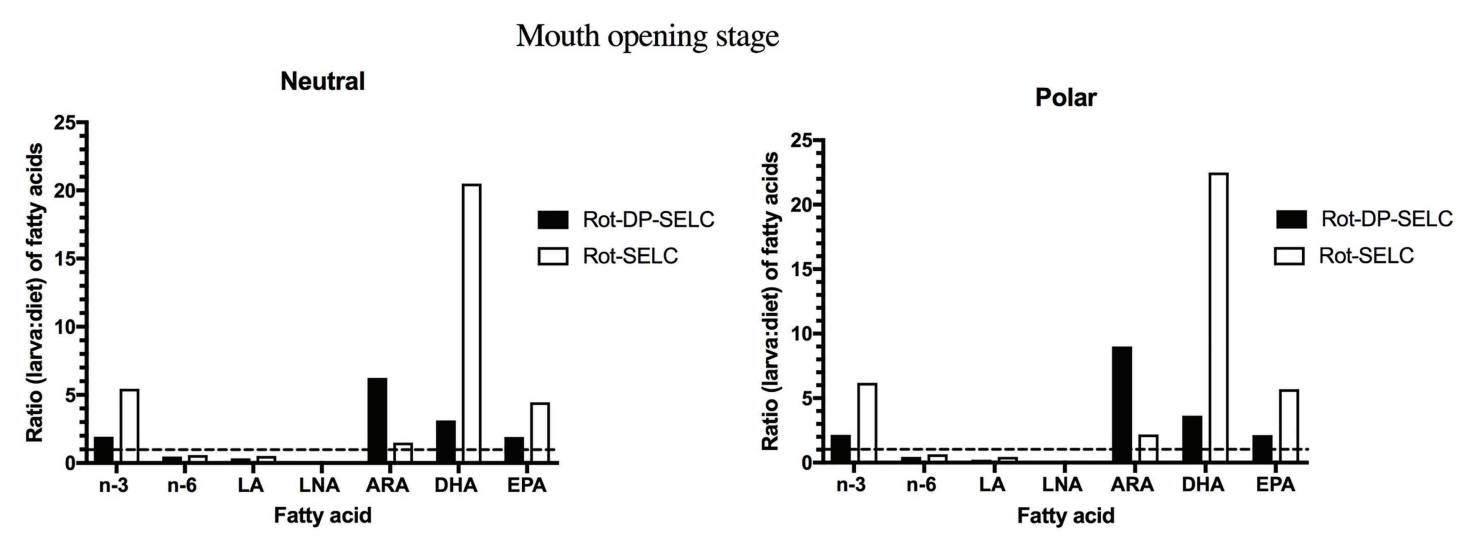

Live prey feeding stage
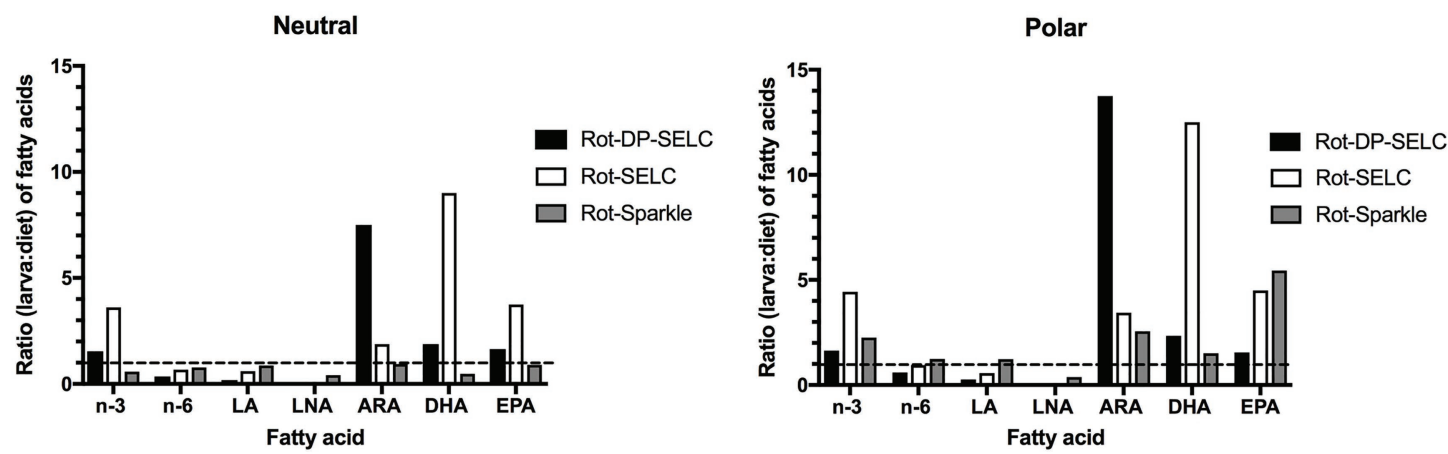

Weaning stage
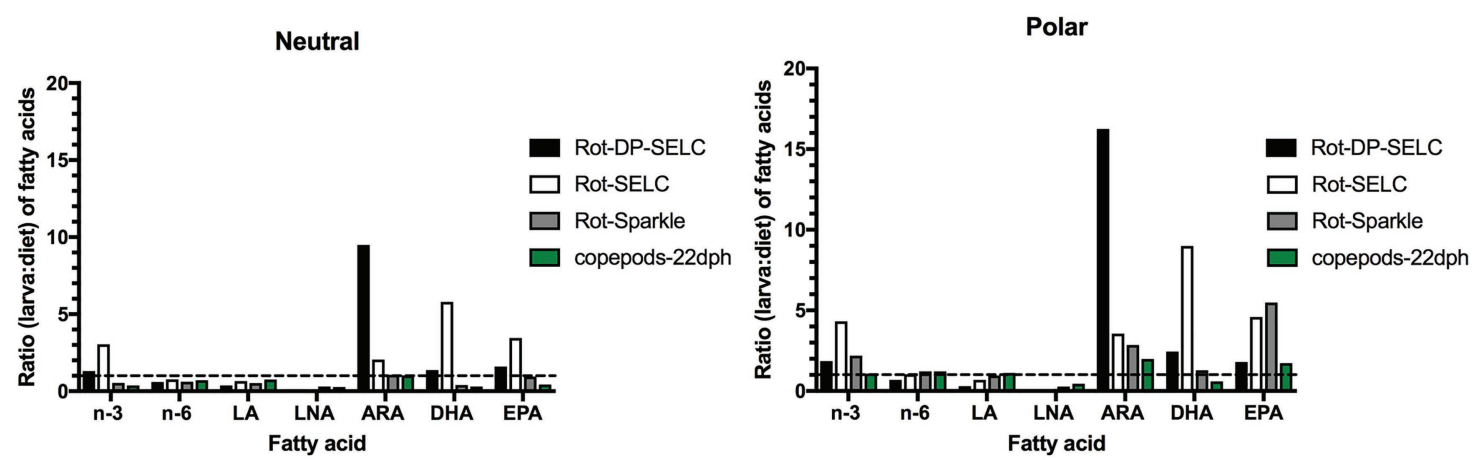

FIGURE 2 | Ratio (larva: diet) of neutral and polar fatty acids in winter flounder (Pseudopleuronectes americanus) larvae at mouth opening (4 DPH), live feeding (15-16 DPH), and beginning of weaning (26 DPH). Larvae had been fed several enriched rotifer diets: Selco 3000 (SELC), DHA Protein Selco (DP-SELC), and sparkle-INVE (Sparkle). Larvae at 22 DPH were fed copepods (Seychelles et al., 2011; Martinez-Silva et al., 2018). The dashed lines (ratio = 1) indicate equal amounts of fatty acids in larvae and in the diet. LA, linoleic acid; LNA, linolenic acid; ARA, arachidonic acid; DHA, docosahexaenoic acid; and EPA, eicosapentaenoic acid.

total FA; Figure 6). The relative percentages of LA and LNA increased over time, from 3 to $5 \%$ of total FA for LA and from 0 to $1 \%$ of total FA for LNA. By comparison golden pompano larvae that were fed several enriched Artemia nauplii diets from 11 to $27 \mathrm{DPH}$, showed a slightly lower requirement for DHA (5\% of total FAs), but relatively similar requirements for EPA, ARA, LA, and LNA $(6.7,1.3,3$, and $1 \%$ of total FAs, respectively; Ma et al., 2016). 
TABLE 4 | Relative percentages of fatty acids in juvenile Florida pompano (T. carolinus; $43.4 \pm 0.2 \mathrm{~g}$ ) muscle, liver, eye, and brain tissues.

\begin{tabular}{lrrrr}
\hline Fatty acid & Muscle & Liver & Eye & Brain \\
\hline 18: 2 n-6 (LA) & $7.41 \pm 4.19$ & $5.25 \pm 2.80$ & $7.18 \pm 3.95$ & $1.74 \pm 1.22$ \\
18: 3 n-3 (LNA) & $1.27 \pm 0.57$ & - & $0.76 \pm 0.18$ & - \\
20: 4 n-6 (ARA) & $1.09 \pm 0.17$ & $1.93 \pm 0.94$ & $0.91 \pm 0.19$ & $1.48 \pm 0.16$ \\
20: 5 n-3 (EPA) & $3.21 \pm 1.19$ & $1.46 \pm 1.07$ & $3.44 \pm 1.63$ & $1.59 \pm 0.30$ \\
22:5 (DPA) & $1.71 \pm 0.60$ & $1.69 \pm 0.82$ & $2.47 \pm 0.67$ & $1.29 \pm 0.27$ \\
22:6 n-3 (DHA) & $10.80 \pm 3.09$ & $15.22 \pm 5.14$ & $11.43 \pm 1.96$ & $14.98 \pm 2.68$ \\
SFA & $38.09 \pm 2.77$ & $40.33 \pm 2.54$ & $38.82 \pm 2.76$ & $47.84 \pm 2.07$ \\
MUFA & $35.34 \pm 4.22$ & $31.91 \pm 6.80$ & $33.36 \pm 5.21$ & $30.61 \pm 1.53$ \\
PUFA & $26.52 \pm 4.16$ & $27.69 \pm 7.01$ & $27.80 \pm 4.79$ & $21.54 \pm 3.01$
\end{tabular}

Juveniles were fed six diets for 8 weeks. Diets contained menhaden fish oil or 25:75 blends of fish oil and standard soybean oil, MUFA-enriched soybean oil, SFA-enriched soybean oil, palm oil, or poultry fat. Data represent mean $\pm S D$ from all diet treatments. $L A$, linoleic acid; $L N A$, linolenic acid; $A R A$, arachidonic acid; EPA, eicosapentaenoic acid; DHA, docosahexaenoic acid; DPA, docosapentaenoic acid; SFA, saturated fatty acids; MUFA, monounsaturated fatty acids; and PUFA, polyunsaturated fatty acids.

The same tendency was observed for winter flounder larvae, with decreased EFA requirements over time. However, EFA requirements at all winter flounder larva stages were higher than for Florida pompano larvae. The relative percentages of DHA, EPA, and ARA were 23, 12, and $4 \%$ of total FA at the mouth-opening stage (Figure 6). The relative percentage of DHA decreased by $75 \%$ at the liveprey feeding and weaning stages ( 8 and $7 \%$ of total FAs, respectively; Figure 6), while the relative percentages of EPA decreased slightly to $9 \%$ of total FA at the live-prey feeding stage and increased to $17 \%$ of total FA at the weaning stage (i.e., $26 \mathrm{DPH}$ ). The relative percentages of ARA decreased by $1 \%$ at both the live-prey feeding and weaning stages. LA requirements were the same during the first days of life and decreased by half (2\% of total FA) at the weaning stage (Figure 6).

Overall, winter flounder larvae had higher requirements for omega 3 (n-3) FA at the mouth-opening stage (36\% of total FA) than at the live-prey feeding and weaning stages (28-27\% of total FA), while requirements for omega 6 (n-6) seemed to increase over time ( $7 \%$ of total FA at the mouth-opening stage vs. $11-12 \%$ of total FA at the live-prey feeding and weaning stages).

Studies on other marine finfish species have shown that the dietary inclusion of n-3 HUFA (i.e., DHA and EPA) and n-6 HUFA (i.e., ARA) improved larval growth, development, and metamorphosis. When examining additional nutritional studies on warm-water and cold-water marine finfish species, we found that EFA requirements during larval development from first feeding to weaning were similar, with few exceptions, to the results reported here. Indeed, common snook (Centropomus indecimalis) larvae at the rotifer-feeding stage (live-prey feeding) showed the same qualitative requirements for EFA as Florida pompano $(15,7$, and $3 \%$ of total FA for DHA, EPA, and ARA, respectively; Hauville et al., 2016). Red drum (Sciaenops ocellatus) larvae at the weaning period (18 DPH) were found to have slightly lower requirements for DHA and EPA (4 and $5 \%$ of total FA, respectively) and similar requirements for ARA
(1\% of total FA) compared to Florida pompano larvae at the same developmental stage (Brinkmeyer and Holt, 1998).

These requirements seemed to be lower in warm-water marine fish at the weaning period, particularly for DHA and ARA, suggesting that the EFA requirements are higher in rapidly growing larvae at the live-feeding stage. In addition, the ratio of DHA to EPA is greater at the live-feeding period (2.2) than during the weaning period (1.0; Figure 6), which is similar to what was observed in red drum larvae as well as larvae from four other species of marine finfish (Watanabe and Kiron, 1995; Brinkmeyer and Holt, 1998). It has been suggested that the high DHA to EPA ratios at the live-feeding stage play a role in stress resistance. The high levels of DHA observed during early larval development for both species reflect the importance of this EFA in larval structural development and in neural and visual functions (Bell et al., 1995a,b; Sargent et al., 1999).

The qualitative requirements for DHA and ARA appeared to be higher in larvae of species that undergo metamorphosis. DHA and ARA values reported in southern flounder (Paralichthys lethostigma) and Atlantic halibut (Hippoglossus hippoglossus) larvae at $15 \mathrm{DPH}$ (live-prey feeding period) were 17 and $5 \%$ of total FA, respectively (Hamre and Harboe, 2008; Alam et al., 2015; Oberg and Fuiman, 2015; Hamre et al., 2020), which is more than twice the percentage of DHA and five times the percentage of ARA found in Florida pompano larvae at the same developmental stage. These differences strongly suggest greater requirements for DHA and ARA during the physiologically demanding metamorphosis process. Hamre et al. (2020) suggested that FA needed to have at least 13\% DHA for normal pigmentation in Atlantic halibut, highlighting the effect of DHA both on eicosanoid production and the development of vision and nervous tissue (Denkins et al., 2005; Roman et al., 2007; Hamre et al., 2020).

An adequate EPA to ARA ratio is important to achieve normal pigmentation and complete eye migration in flatfish species; this has been reported for turbot (Scophthalmus maximus), Atlantic halibut, Senegalese sole (Solea senegalensis), and yellowtail flounder (Limanda ferruginea; McEvoy et al., 1998; Estévez et al., 1999; Copeman et al., 2002; Villalta et al., 2005). The EPA to ARA ratio in winter flounder was 3.0 during early larval development (4 and $15 \mathrm{DPH}$ ) and close to 6.0 at the weaning period (22-26 DPH; Figure 6). For Florida pompano, the highest ratio (ratio $=7.0$ ) was reported at the weaning period, but other than that, the ratio did not exceed two. A previous study on turbot larvae has concluded that it is important to consider the ratio of DHA to EPA and found that it is positively correlated with pigmentation success (Rainuzzo et al., 1994).

At the juvenile stage, the qualitative requirement for DHA was similar between the two species ( $12 \%$ of total FA). However, $0+$ juvenile winter flounder were much smaller than juvenile Florida pompano ( 1 vs. $42 \mathrm{~g}$ ), thus their DHA requirement might be higher for the same stage of development (Figure 6). The different DHA requirements can also be coupled with water temperatures of the different habitats, with cold water fish species generally having higher DHA levels than more temperate species (Hamre et al., 2020). In general, poikilotherm fish counteract the lower temperature effect to maintain their 


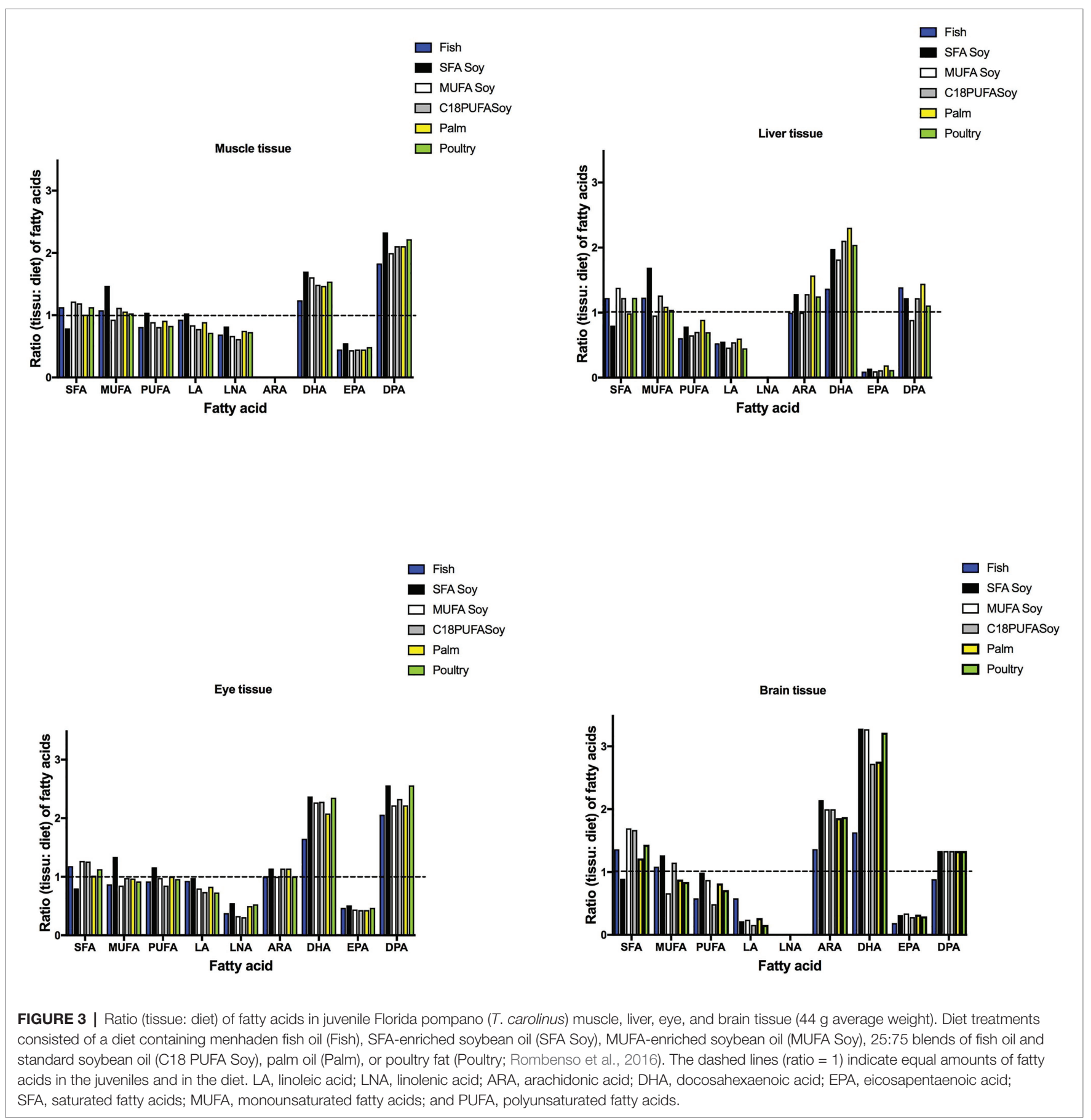

metabolism by remodeling fatty acids in the membrane. In cold conditions, the integration of PUFA, particularly DHA, in phospholipids maintains membrane fluidity and metabolic rate, a process known as homeoviscous adaptation (Hazel, 1995). Thus, cold-water species should require more DHA to maintain their physiological function, as observed in this comparison between winter flounder and Florida pompano. EPA and ARA requirements seemed to be higher in winter flounder, ranging from $6 \%$ at the early settlement stage to $11 \%$ at the $0+$ juvenile stage for EPA and from 3 to $4 \%$ for
ARA for the same stages, respectively (EPA: ARA ratio is approximately 2.5; Figure 6). Hamre et al. (2020) showed that Atlantic halibut juveniles would need a combination of at least $13 \%$ DHA of total FA and a higher ratio of EPA to ARA (ratio $=3.5$ ) to promote growth and survival of young juveniles.

One of the most interesting differences between the two species was the presence of LA and LNA in Florida pompano larvae and juveniles at all stages, while LNA was absent in winter flounder. Jackson et al. (2020) recently published data suggesting that Florida pompano juveniles have some 


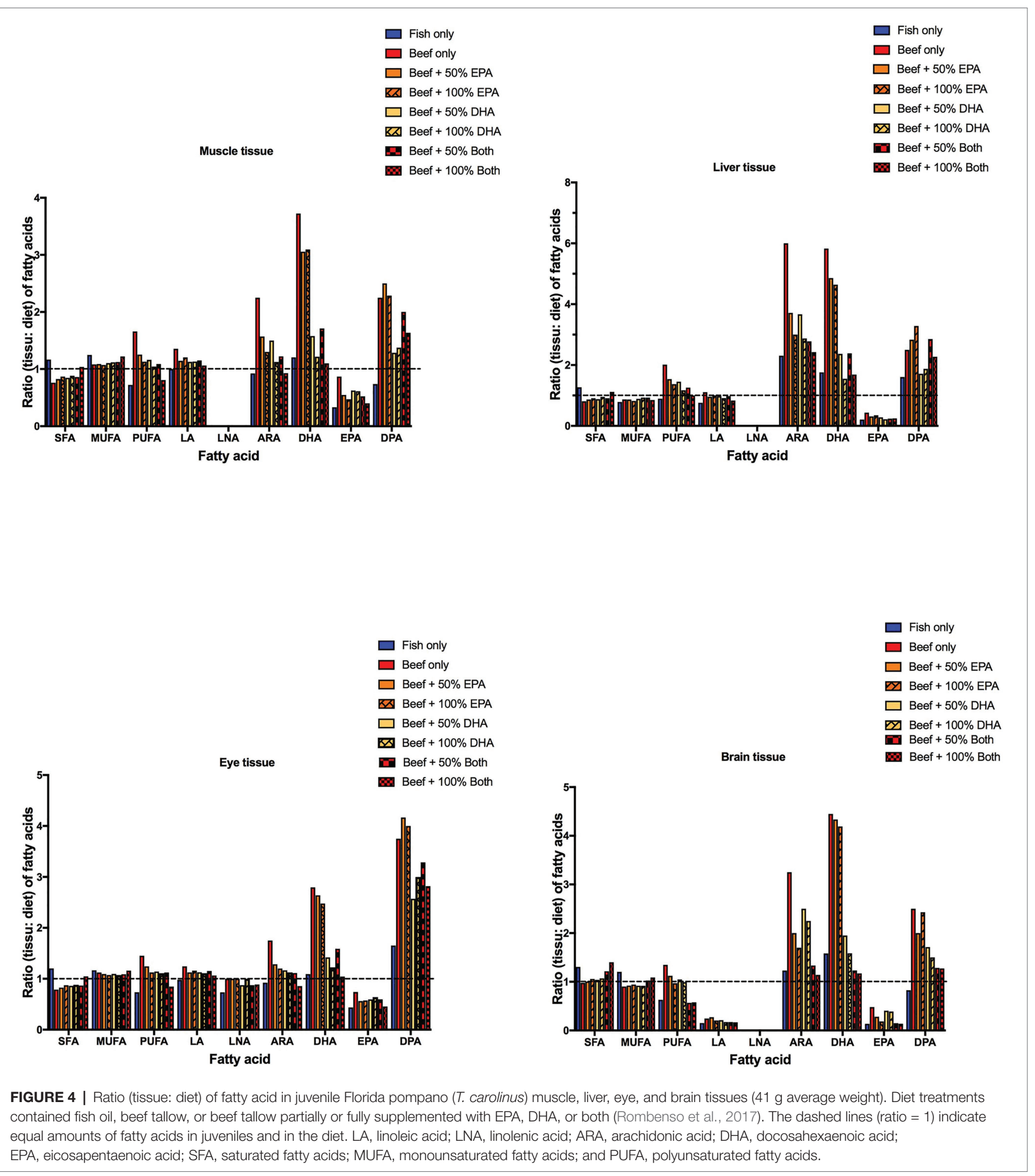

capacity to elongate and desaturate fatty acids from C18 precursors (i.e., LA and LNA) and may be able to survive on diets containing C18 PUFA. However, the authors strongly recommend that juveniles be directly provided with HUFA to perform optimally (Jackson et al., 2020). Recent studies concluded that golden pompano juveniles (ranging in sizes from 8 to $50 \mathrm{~g}$ ), a species belonging to the same family as the Florida pompano, might have low capacity to biosynthesize HUFA (Liu et al., 2018; Li et al., 2020; Wang et al., 2020). Wang et al. (2020) have found that golden pompano juveniles may have the capability of converting EPA to DHA but lack the $\Delta 5$ desaturation activity, required 
TABLE 5 | Relative percentages of neutral and polar fatty acids in winter flounder (P. americanus) juveniles at the beginning of settlement (38 DPH), 30 DPS, and at the $0+$ juvenile stage (60 and 90 DPS).

\begin{tabular}{|c|c|c|c|c|c|}
\hline & \multicolumn{4}{|c|}{ Juveniles } & \multirow[t]{2}{*}{ Reference } \\
\hline & Settlement & $\begin{array}{l}\text { Early settled } \\
\text { juveniles }\end{array}$ & $0+j$ & iles & \\
\hline Neutral fatty acid & $38 \mathrm{DPH}$ & 30 DPS & 60 DPS & 90 DPS & \\
\hline 18: 2 n-6 (LA) & $5.40 \pm 0.00$ & $5.55 \pm 0.07$ & 7.27 & 7.60 & 38 DPH and 30 DPS: Seychelles et al., 2011, and Bélanger et al., 2018 \\
\hline 18: 3 n-3 (LNA) & 0 & 0 & 0 & 0 & 60 and 90 DPS: Bélanger et al., 2018 \\
\hline 20: 4 n-6 (ARA) & $1.65 \pm 0.92$ & $1.10 \pm 0.14$ & 3.15 & 1.53 & \\
\hline 20: 5 n-3 (EPA) & $2.50 \pm 0.0$ & $2.40 \pm 0.14$ & 9.01 & 6.90 & \\
\hline $22: 6$ n-3 (DHA) & $1.00 \pm 0.00$ & $1.00 \pm 0.00$ & 10.57 & 6.80 & \\
\hline Total n-3 & $4.10 \pm 0.14$ & $3.70 \pm 0.00$ & 21.01 & 14.44 & \\
\hline Total n-6 & $7.05 \pm 0.92$ & $6.65 \pm 0.07$ & 16.27 & 15.68 & \\
\hline SFA & & & & 28.00 & Bélanger et al., 2018 \\
\hline MUFA & & & & 34.05 & \\
\hline PUFA & & & & 34.95 & \\
\hline \multicolumn{6}{|l|}{ Polar fatty acid } \\
\hline 18: 2 n-6 (LA) & $7.20 \pm 0.28$ & $7.85 \pm 0.07$ & 5.19 & 7.02 & 38 DPH and 30 DPS: Seychelles et al., 2011, and Bélanger et al., 2018 \\
\hline 18: 3 n-3 (LNA) & 0 & 0 & 0 & 0 & 60 and 90 DPS: Bélanger et al., 2018 \\
\hline 20: 4 n-6 (ARA) & $3.30 \pm 0.00$ & $3.00 \pm 0.00$ & 4.60 & 4.03 & \\
\hline 20: 5 n-3 (EPA) & $6.50 \pm 0.00$ & $6.00 \pm 0.00$ & 10.88 & 10.88 & \\
\hline 22:6 n-3 (DHA) & $3.75 \pm 1.77$ & $2.50 \pm 0.71$ & 12.53 & 10.81 & \\
\hline Total n-3 & $12.45 \pm 1.63$ & $6.95 \pm 3.61$ & 23.99 & 22.56 & \\
\hline Total n-6 & $10.65 \pm 0.35$ & $14.0 \pm 4.24$ & 13.99 & 15.79 & \\
\hline SFA & & & & 33.35 & Bélanger et al., 2018 \\
\hline MUFA & & & & 23.55 & \\
\hline PUFA & & & & 41.60 & \\
\hline
\end{tabular}

Data represent mean $\pm S D$ from all diet treatments. LA, linoleic acid; LNA, linolenic acid; ARA, arachidonic acid; EPA, eicosapentaenoic acid; DHA, docosahexaenoic acid; SFA, saturated fatty acids; MUFA, monounsaturated fatty acids; and PUFA, polyunsaturated fatty acids.

to convert 20:3 n-6 and 20:4 n-3 to ARA and EPA, respectively, suggesting incomplete HUFA biosynthesis ability.

It is hypothesized that trophic level is a better predictor of a requirement for C18 PUFA vs. HUFA rather than the species' thermal or salinity preference (Jackson et al., 2020; Trushenski and Rombenso, 2020). It is interesting to note that Florida pompano and winter flounder, despite their contrasting thermal environments, both belong to the same trophic level (Florida pompano trophic level $=3.5$, Froese and Pauly, 2016; winter flounder trophic level $=3.6 \pm 0.1$, Murdy et al., 1997), which might explain some of the similarities in EFA requirements observed here. The validation of this hypothesis would change our way of investigating requirements for fatty acids in fish species and thus allow standardization of feed formulations for different developmental stages.

\section{CONCLUSION}

Essential fatty acid requirements vary qualitatively and quantitatively during fish ontogeny, with the larval and juvenile stages being arguably the most critical periods. In this review, we give a comprehensive synthesis of these requirements, highlighting the similarities and differences between two species occupying contrasting environments: a warm-water tropical species (Florida pompano) and a cold-water flatfish species (winter flounder). In general, we found that the young larvae of both species are characterized by greater requirements for n-3 and n-6 HUFA compared to larvae at the live-feeding and weaning stages as well as juveniles. Florida pompano larvae at the live-feeding stage require more DHA, EPA, and ARA than larvae at the weaning stage, with minimal levels probably around 15,7 , and $3.5 \%$ of total FA, respectively, for young larvae (i.e., $9 \mathrm{DPH}$ ) and 9, 5, and $0.5 \%$ of total FA for larvae at the weaning stage. Nevertheless, none of the diets seemed to fully satisfy the EFA needs for both larval stages. Studies on the EFA requirements during early larval development in winter flounder suggest that the physiological needs of larvae were not met for all the rotifer-enriched diets tested. Ratios of DHA, EPA, and ARA in the polar lipid fraction related to diet were systematically well over 1.0, indicating strong retention. Ratios $\leq 1$ were only obtained when larvae at the weaning stage were fed copepods, suggesting a minimal qualitative requirement of $12 \% \mathrm{DHA}, 10 \% \mathrm{EPA}$, and $6 \% \mathrm{ARA}$ of total FA at this stage, and up to $20 \%$ DHA in younger larvae. During metamorphosis, winter flounder - like many flatfish species - has specific EFA requirements necessary to achieve correct pigmentation and eye migration. Thus, an early supply of dietary DHA, EPA, and ARA emphasizing the importance of dietary DHA: EPA: ARA ratios is essential for successful pigmentation and eye migration. Concerning juvenile development, the qualitative EFA requirements seem to be similar in both species, with slightly higher needs for EPA and ARA in winter flounder. Diets containing around 15\% DHA, 3\% EPA, 2\% DPA, and 2\% ARA, for a total PUFA below 30\% of total FA, seem to be appropriate for Florida pompano 


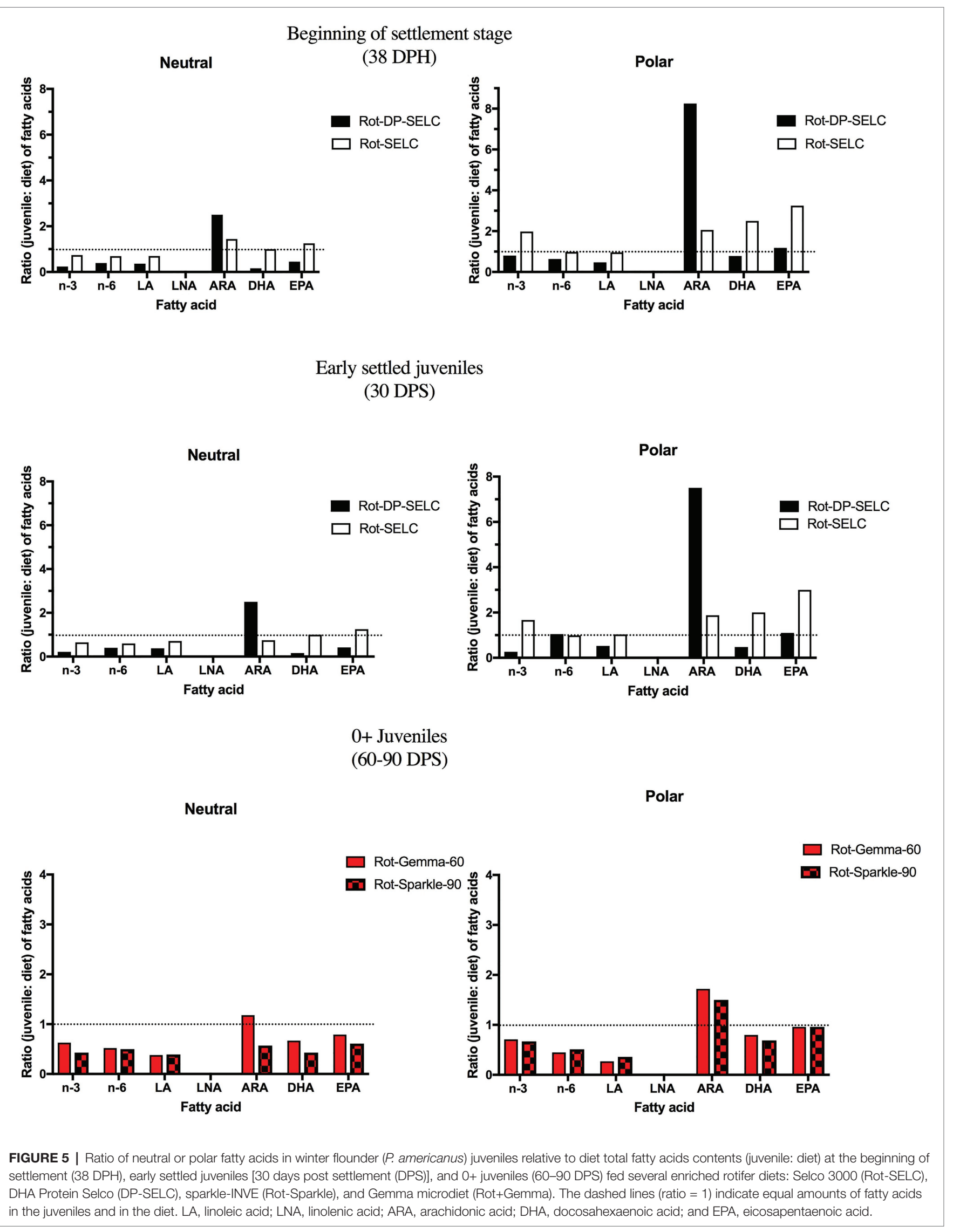




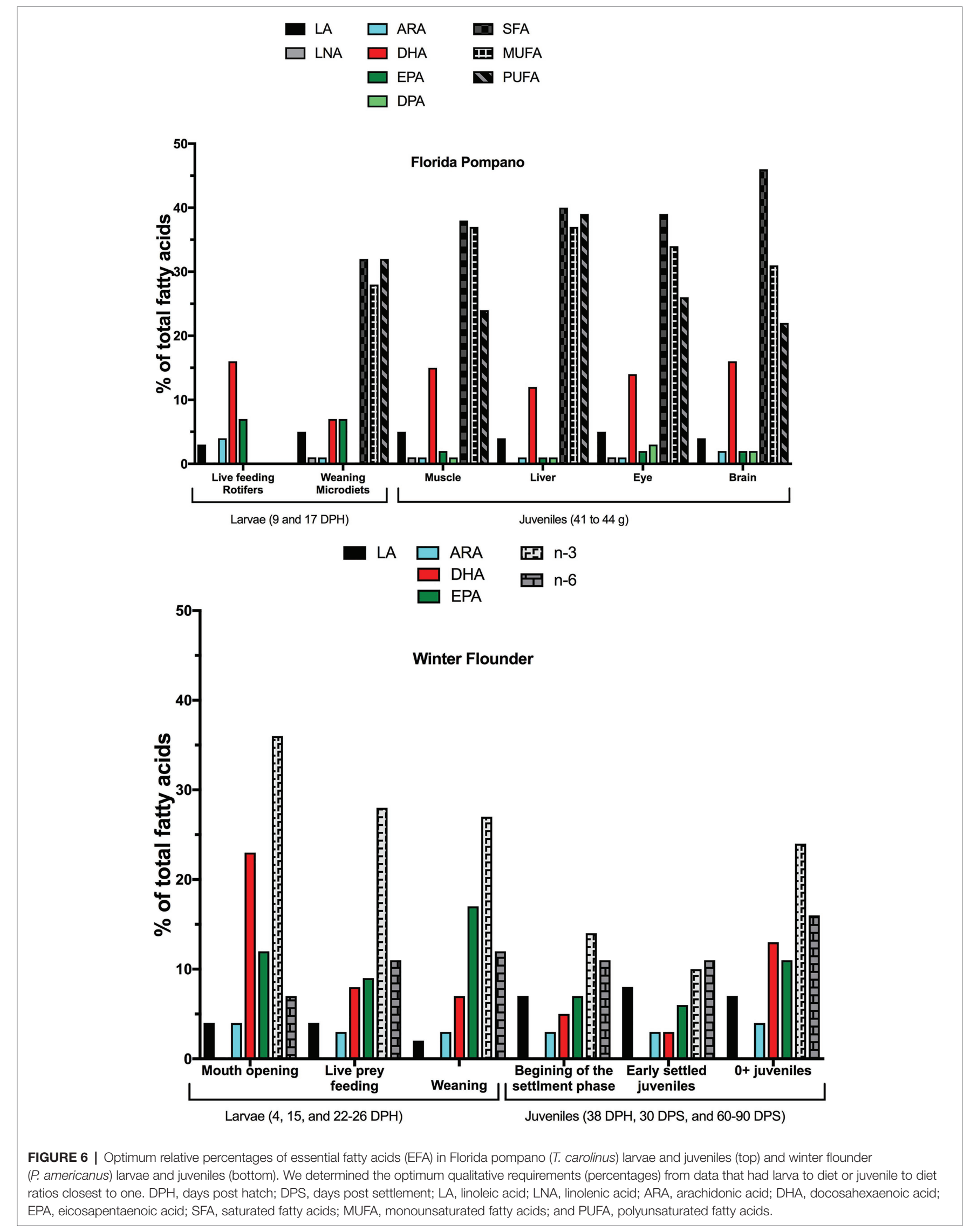


development, while diets with 12\% DHA, 10\% EPA, and 5\% ARA, for a total of $40 \%$ PUFA, could be better for juvenile winter flounder development.

Identifying the EFA needs in marine fish larvae is particularly difficult because of the fishes' small size and often poorly developed digestive system. The complexity and time-consuming effort of determining precise microdiets led to the use of live feeds, such as rotifers and Artemia, but these are often inadequate for marine larvae and require enrichment in HUFA. HUFA enrichments of live feeds do not provide sufficient DHA and adequately balanced levels of HUFA (Tocher, 2010), thus it is necessary to continue work toward developing nutritionally balanced microdiets that satisfy the physiological needs of marine fish larvae. In addition, the growing aquaculture industry - by pressing the need for marine fish meal and oils to be replaced with plant-derived products - has reintroduced the need to identify the precise qualitative and quantitative EFA requirements for marine fish larvae and juveniles. There must be detailed knowledge of the molecular and biochemical bases of HUFA requirements and metabolism: the physiological needs of a fish species to achieve optimal growth and stay healthy are different from the requirements to maintain nutritional quality, which leads to health benefits for human consumers.

\section{REFERENCES}

Alam, M. S., Watanabe, W. O., Rezek, T. C., Myers, A. R., Carroll, P. M., and Daniels, H. V. (2015). Growth performance, survival and body composition of southern flounder Paralichthys lethostigma larvae fed different formulated microdiets. Aquac. Res. 46, 1924-1936. doi: 10.1111/are.12347

Bélanger, M., Turcotte, F., Tremblay, R., Lambert, Y., Litvak, M., and Audet, C. (2018). Influence of the timing of weaning on growth and survival of juvenile winter flounder (Pseudopleuronectes americanus). Can. J. Zool. 96, 1291-1298. doi: $10.1139 / \mathrm{cjz}-2018-0004$

Bell, M. V., Batty, R. S., Dick, J. R., Fretwell, K., Navarro, J. C., and Sargent, J. R. (1995b). Dietary deficiency of docosahexaenoic acid impairs vision at low light intensities in juvenile herring (Clupea harengus L.). Lipids 30, 443-449.

Bell, J. G., Castell, J. D., Tocher, D. R., Macdonald, F. M., and Sargent, J. R. (1995a). Effects of different dietary arachidonic acid: docosahexaenoic acid ratios on phospholipid fatty acid compositions and prostaglandin production in juvenile turbot (Scophthalmus maximus). Fish Physiol. Biochem. 14, 139-151.

Brinkmeyer, R. L., and Holt, G. J. (1998). Highly unsaturated fatty acids in diets for red drum (Sciaenops ocellatus) larvae. Aquaculture 161, 253-268. doi: 10.1016/S0044-8486(97)00274-3

Budge, S. M., Iverson, S. J., and Koopman, H. N. (2006). Studying trophic ecology in marine ecosystems using fatty acids: a primer on analysis and interpretation. Mar. Mamm. Sci. 22, 759-801. doi: 10.1111/j.1748-7692.2006.00079.x

Castell, J., Blair, T., Neil, S., Howes, K., Mercer, S., Reid, J., et al. (2003). The effect of different HUFA enrichment emulsions on the nutritional value of rotifers (Brachionus plicatilis) fed to larval haddock (Melanogrammus aeglefinus). Aquac. Int. 11, 109-117. doi: 10.1023/A:1024154106656

Cavalin, F. G., and Weirich, C. R. (2009). Larval performance of aquacultured Florida pompano (Trachinotus carolinus) fed rotifers (Brachionus plicatilis) enriched with selected commercial diets. Aquaculture 292, 67-73. doi: 10.1016/j.aquaculture.2009.03.042

Copeman, L. A., Parrish, C. C., Brown, J. A., and Harel, M. (2002). Effects of docosahexaenoic, eicosapentaenoic, and arachidonic acids on the early growth, survival, lipid composition and pigmentation of yellowtail flounder (Limanda ferruginea): a live food enrichment experiment. Aquaculture 210, 285-304. doi: 10.1016/S0044-8486(01)00849-3

Denkins, Y., Kempf, D., Ferniz, M., Nileshwar, S., and Marchetti, D. (2005). Role of omega-3 polyunsaturated fatty acids on cyclooxygenase- 2 metabolism

\section{AUTHOR CONTRIBUTIONS}

SM and RT have developed the idea and all authors contributed to this review. All authors contributed to the article and approved the submitted version.

\section{FUNDING}

Mention of trade names or commercial products in this publication is solely for the purpose of providing specific information and does not imply recommendation or endorsement by the U.S. Department of Agriculture (USDA). USDA is an equal opportunity provider and employer. This work was supported in part (the Florida pompano work) by the U.S. Department of Agriculture, Agricultural Research Service by cooperative agreement number 59-6034-9-007 with Florida Atlantic University's Harbor Branch Oceanographic Institute. Studies on winter flounder were supported by the Conseil National de Recherche en Sciences et Génie (CRSNG), Fonds de Recherche du Québec Nature et Technologies (FRQNT), and Ressources Aquatiques Québec - Regroupement Stratégique FRQNT. in brain-metastatic melanoma. J. Lipid Res. 46, 1278-1284. doi: 10.1194/jlr. M400474-JLR200

Drillet, G., and Lombard, F. (2015). A first step towards improving copepod cultivation using modelling: the effects of density, crowding, cannibalism, tank design and strain selection on copepod egg production yields. Aquac. Res. 46, 1638-1647. doi: 10.1111/are.12317

Estévez, A., Mcevoy, L. A., Bell, J. G., and Sargent, J. R. (1999). Growth, survival, lipid composition and pigmentation of turbot (Scophthalmus maximus) larvae fed live-prey enriched in arachidonic and eicosapentaenoic acids. Aquaculture 180, 321-343. doi: 10.1016/S0044-8486(99)00209-4

Froese, R., and Pauly, D. (2016). FishBase. Available at: www.fishbase.org (Accessed September 2020).

Fu, Z., Yang, R., Zhou, S., Ma, Z., and Zhang, T. (2021). Effects of rotifers enriched with different enhancement products on larval performance and jaw deformity of golden pompano larvae Trachinotus ovatus (Linnaeus, 1758). Front. Mar. Sci. 7:626071. doi: 10.3389/fmars.2020.626071

Gendron, L., Tremblay, R., Belvin, S., Génard, B., Motnikar, S., and Côté, J. (2013). Condition, survival and growth in situ of hatchery-reared stage IV lobster (Homarus americanus) fed Artemia and lipid-rich wild zooplankton. Aquaculture 416-417, 380-389. doi: 10.1016/j.aquaculture. 2013.08.003

Glencross, B. D. (2009). Exploring the nutritional demand for essential fatty acids by aquaculture species. Rev. Aquac. 1, 71-124. doi: 10.1111/j.1753-5131. 2009.01006.x

Gurr, M. I., Harwood, J. L., Frayn, K. N., Murphy, D. J., and Michell, R. H. (2016). Lipids: Biochemistry, Biotechnology and Health. 6th Edn. West Sussex, UK: Wiley-Blackwell, 448.

Hamre, K., Erstad, B., de Kok, J., Norberg, B., and Harboe, T. (2020). Change in nutrient composition of Artemia grown for 3-4 days and effects of feeding on grown Artemia on performance of Atlantic halibut (Hippoglossus hippoglossus, L.) larvae. Aquac. Nutr. 26, 1542-1554. doi: 10.1111/anu.13101

Hamre, K., and Harboe, T. (2008). Critical levels of essential fatty acids for normal pigmentation in Atlantic halibut (Hippoglossus hippoglossus L.) larvae. Aquaculture 277, 101-108. doi: 10.1016/j.aquaculture.2008.02.020

Hauville, M. R., Main, K. L., Migaud, H., and Gordon Bell, J. (2016). Fatty acid utilization during the early larval stages of Florida pompano (Trachinotus carolinus) and common Snook (Centropomus undecimalis). Aquac. Res. 47, 1443-1458. doi: 10.1111/are.12602 
Hauville, M. R., Zambonino-Infante, J. L., Bell, G., Migaud, H., and Main, K. L. (2014). Impacts of three different microdiets on Florida pompano, Trachinotus carolinus, weaning success, growth, fatty acid incorporation and enzyme activity. Aquaculture 422-423, 268-276. doi: 10.1016/j. aquaculture.2013.12.006

Hawkyard, M., Laurel, B., Barr, Y., Hamre, K., and Langdon, C. (2015). Evaluation of liposomes for the enrichment of rotifers (Brachionus sp.) with taurine and their subsequent effects on the growth and development of northern rock sole (Lepidopsetta polyxystra) larvae. Aquaculture 441, 118-125. doi: 10.1016/j.aquaculture.2015.02.012

Hazel, J. R. (1995). Thermal adaptation in biological membranes: is homeoviscous adaptation the explanation? Annu. Rev. Physiol. 57, 19-42. doi: 10.1146/ annurev.ph.57.030195.000315

Izquierdo, M. S., Socorro, J., Arantzamendi, L., and Hernández-Cruz, C. M. (2000). Recent advances in lipid nutrition in fish larvae. Fish Physiol. Biochem. 22, 97-107. doi: 10.1023/A:1007810506259

Jackson, C. J., Trushenski, J. T., and Schwarz, M. H. (2020). Assessing polyunsaturated fatty acid essentiality in Florida pompano. N. Am. J. Aquac. 82, 293-306. doi: 10.1002/naaq.10140

Jardine, T. D., Galloway, A. W. E., and Kainz, M. J. (2020). Unlocking the power of fatty acids as dietary tracers and metabolic signals in fishes and aquatic invertebrates. Philos. Trans. R. Soc. Lond. B. Biol. 375:20190639. doi: 10.1098/rstb.2019.0639

Langdon, C. J., and Waldock, M. J. (1981). The effect of algal and artificial diets on the growth and fatty acid composition of Crassostrea gigas spat. J. Mar. Biol. Assoc. U. K. 61, 431-448.

Li, M., Xu, C., Ma, Y., Ye, R., Chen, H., Xie, D., et al. (2020). Effects of dietary n-3 highly unsaturated fatty acids levels on growth, lipid metabolism and innate immunity in juvenile golden pompano (Trachinotus ovatus). Fish Shellfish Immunol. 105, 177-185. doi: 10.1016/j.fsi.2020.06.060

Liu, K., Liu, H., Chi, S., Dong, X., Yang, Q., and Tan, B. (2018). Effects of different dietary lipid sources on growth performance, body composition and lipid metabolism-related enzymes and genes of juvenile golden pompano, Trachinotus ovatus. Aquac. Res. 49, 717-725. doi: 10.1111/ are. 13502

Ma, Z., Zheng, P., He, D., Jiang, S., and Qin, J. G. (2016). Effect of feeding Artemia nauplii enriched with different enhancement products on larval performance of golden pompano Trachinotus ovatus (Linnaeus, 1758). Indian J. Fish. 63, 62-69. doi: 10.21077/ijf.2016.63.2.50560-08

Martinez-Silva, M. A., Audet, C., Winkler, G., and Tremblay, R. (2018). Prey quality impact on the feeding behavior and lipid composition of winter flounder (Pseudopleuronectes americanus) larvae. Aquac. Fish 3, 145-155. doi: 10.1016/j.aaf.2018.06.003

McEvoy, L. A., Estevez, A., Bell, J. G., Shields, R. J., Gara, B., and Sargent, J. R. (1998). Influence of dietary levels of eicosapentaenoic and arachidonic acid on the pigmentation success of turbot (Scophtalmus maximus) and halibut (Hippoglossus hippoglossus). Bull. Aquac. Assoc. Can. 98, 17-20.

Mercier, L., Audet, C., De La Noüe, J., Parent, B., Parrish, C. C., and Ross, N. W. (2004). First feeding of winter flounder (Pseudopleuronectes americanus) larvae: use of Brachionus plicatilis acclimated at low temperature as live prey. Aquaculture 229, 361-376. doi: 10.1016/S0044-8486(03)00399-5

Monroig, Ó., Navarro, J. C., Amat, I., González, P., Amat, F., and Hontoria, F. (2003). Enrichment of Artemia nauplii in PUFA, phospholipids, and watersoluble nutrients using liposomes. Aquac. Int. 11, 151-161. doi: 10.1023/A: 1024199305622

Murdy, E. O., Birdsong, R. S., and Musick, J. A. (1997). Fishes of Chesapeake Bay. Washington and London: Smithsonian Institution Press, 324.

Oberg, E. W., and Fuiman, L. A. (2015). Linking fatty acids in the diet and tissues to quality of larval southern flounder (Paralichthys lethostigma). J. Exp. Mar. Biol. Ecol. 467, 7-15. doi: 10.1016/j.jembe.2015.02.021

Øie, G., Reitan, K. I., Evjemo, J. O., Støttrup, J., and Olsen, Y. (2011). "Live feeds," in Larval fish nutrition. ed. G. J. Holt (West Sussex, UK: WileyBlackwell), 307-651.

Parrish, C. C. (2013). Lipids in marine ecosystems. ISRN Oceanogr. 2013:604045. doi: $10.5402 / 2013 / 604045$

Parrish, C. C., Whiticar, M., and Puvanendran, V. (2007). Is $\omega 6$ docosapentaenoic acid an essential fatty acid during early ontogeny in marine fauna? Limnol. Oceanogr. 52, 476-479. doi: 10.4319/lo.2007.52.1.0476
Pernet, F., and Tremblay, R. (2004). Effect of varying levels of dietary essential fatty acid during early ontogeny of the sea scallop Placopecten magellanicus. J. Exp. Mar. Biol. Ecol. 310, 73-86. doi: 10.1016/j.jembe.2004.04.001

Pond, D. W., and Tarling, G. A. (2011). Phase transitions of wax esters adjust buoyancy in diapausing Calanoides acutus. Limnol. Oceanogr. 56, 1310-1318. doi: $10.4319 /$ lo.2011.56.4.1310

Rainuzzo, J. R., Reitan, K. I., Jørgensen, L., and Olsen, Y. (1994). Lipid composition in turbot larvae fed live feed cultured by emulsions of different lipid classes. Comp. Biochem. Physiol. Part A Physiol. 107, 699-710. doi: 10.1016/0300-9629 (94) $90372-7$

Rocha, G. S., Katan, T., Parrish, C. C., and Kurt Gamperl, A. (2017). Effects of wild zooplankton versus enriched rotifers and Artemia on the biochemical composition of Atlantic cod (Gadus morhua) larvae. Aquaculture 479, 100-113. doi: 10.1016/j.aquaculture.2017.05.025

Roman, A., Schreher, J., Mackenzie, A., and Nathanielsz, P. (2007). Omega-3 fatty acids and decidual cell prostaglandin production in response to the inflammatory cytokine IL-1ß. Am. J. Obstet. Gynecol. 195, 1693-1699. doi: 10.1016/j.ajog.2006.04.009

Rombenso, A. N., Trushenski, J. T., and Schwarz, M. H. (2016). Fish oil replacement in feeds for juvenile Florida pompano: composition of alternative lipid influences degree of tissue fatty acid profile distortion. Aquaculture 458, 177-186. doi: 10.1016/j.aquaculture.2016.03.009

Rombenso, A. N., Trushenski, J. T., and Schwarz, M. H. (2017). Beef tallow is suitable as a primary lipid source in juvenile Florida pompano feeds. Aquac. Nutr. 23, 1274-1286. doi: 10.1111/anu.12502

Sargent, J., Mcevoy, L., Estevez, A., Bell, G., Bell, M., Henderson, J., et al. (1999). Lipid nutrition of marine fish during early development: current status and future directions. Aquaculture 179, 217-229. doi: 10.1016/S0044-8486(99)00191-X

Seychelles, L. H., Audet, C., Tremblay, R., Fournier, R., and Pernet, F. (2009). Essential fatty acid enrichment of cultured rotifers (Brachionus plicatilis, Müller) using frozen-concentrated microalgae. Aquac. Nutr. 15, 431-439. doi: $10.1111 /$ j.1365-2095.2008.00608.x

Seychelles, L. H., Audet, C., Tremblay, R., Lemarchand, K., and Pernet, F. (2011). Bacterial colonization of winter flounder Pseudopleuronectes americanus fed live feed enriched with three different commercial diets. Aquac. Nutr. 17, 196-206. doi: 10.1111/j.1365-2095.2009.00750.x

Seychelles, L., Doiron, K., Audet, C., Tremblay, R., Pernet, F., and Lemarchand, K. (2013). Impact of arachidonic acid enrichment of live rotifer prey on bacterial communities in rotifer and larval fish cultures. Can. J. Microbiol. 59, 189-196. doi: $10.1139 /$ cjm-2012-0564

Tocher, D. R. (2010). Fatty acid requirements in ontogeny of marine and freshwater fish. Aquac. Res. 41, 717-732. doi: 10.1111/j.1365-2109.2008.02150.x

Tocher, D. R., Bendiksen, E. Å., Campbell, P. J., and Bell, J. G. (2008). The role of phospholipids in nutrition and metabolism of teleost fish. Aquaculture 280, 21-34. doi: 10.1016/j.aquaculture.2008.04.034

Trushenski, J. T., and Rombenso, A. N. (2020). Trophic levels predict the nutritional essentiality of polyunsaturated fatty acids in fish - introduction to a special section and a brief synthesis. N. Am. J. Aquac. 82, 241-250. doi: $10.1002 /$ naaq. 10137

Vagner, M., De Montgolfier, B., Sévigny, J.-M., Tremblay, R., and Audet, C. (2013). Expression of genes involved in key metabolic processes during winter flounder (Pseudopleuronectes americanus) metamorphosis. Can. J. Zool. 91, 156-163. doi: 10.1139/cjz-2012-0240

Villalta, M., Estévez, A., and Bransden, M. P. (2005). Arachidonic acid enriched live prey induces albinism in Senegal sole (Solea senegalensis) larvae. Aquaculture 245, 193-209. doi: 10.1016/j.aquaculture.2004.11.035

Villalta, M., Estévez, A., Bransden, M. P., and Bell, J. G. (2008). Effects of dietary eicosapentaenoic acid on growth, survival, pigmentation and fatty acid composition in Senegal sole (Solea senegalensis) larvae during the Artemia feeding period. Aquac. Nutr. 14, 232-241. doi: 10.1111/j.1365-2095.2007.00522.x

Wang, S., Wang, M., Zhang, H., Yan, X., Guo, H., You, C., et al. (2020). Long-chain polyunsaturated fatty acid metabolism in carnivorous marine teleosts: insight into the profile of endogenous biosynthesis in golden pompano Trachinotus ovatus. Aquac. Res. 51, 623-635. doi: 10.1111/are.14410

Watanabe, T., and Kiron, V. (1995). "Red Sea bream (Pagurus major)," in Broodstock Management and Egg and Larvae Quality. eds. N. R. Bromage and R. J. Roberts (Cambridge, MA: Blackwell), 398-413.

Yaragina, N., Ådlandsvik, B., Dolgov, A., and Marshall, C. (2000). Reconstructing the stock-recruit relationship for northeast artic cod using a bioenergetic 
index of reproductive potential. Can. J. Fish. Aquat. Sci. 57, 2433-2442. doi: $10.1139 /$ cjfas- $57-12-2433$

Conflict of Interest: The authors declare that the research was conducted in the absence of any commercial or financial relationships that could be construed as a potential conflict of interest.
Copyright (๑) 2021 Mejri, Tremblay, Audet, Wills and Riche. This is an open-access article distributed under the terms of the Creative Commons Attribution License (CC BY). The use, distribution or reproduction in other forums is permitted, provided the original author(s) and the copyright owner(s) are credited and that the original publication in this journal is cited, in accordance with accepted academic practice. No use, distribution or reproduction is permitted which does not comply with these terms. 